\title{
Subject Index for the December Supplement Issue 2012
}

A

Adrenal hyperplasia ... . . . . . . . . . . . . S78

C

Carcinoma cervix ..................... S38

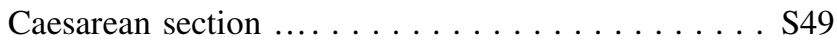

Scar rupture ... . . . . . . . . . . . . . . . S99

CA cervix ... . . . . . . . . . . . . . . S59, S89

Choriocarcinoma ... . . . . . . . . . . . . . . S97

D

Drugs in pregnancy $\ldots \ldots \ldots \ldots \ldots \ldots \ldots$. 333

$\mathbf{E}$

Ectopic cervical .................... S1

Ovarian ................... S10

Eclampsia ... . . . . . . . . . . . . . . . . . S27

Endometriosis ... . . . . . . . . . . . . . . . . . S94

\section{F}

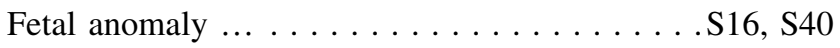

Fallopian tube carcinoma ... . . . . . . . . . . S61

\section{G}

G 1 disorders $\ldots \ldots \ldots \ldots \ldots \ldots \ldots \ldots \ldots \ldots$. . . . . . . 6

Genetic abnormality ................. S65

Genetic disorder ................... S75, S83

H

Heart diseases in pregnancy
Hematological disorders in pregnancy

$. S 23, S 29$

$\mathbf{M}$

Multiple fetal pregnancy ................ S19

Multi fetal pregnancy ... . . . . . . . . . . . S43

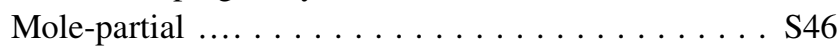

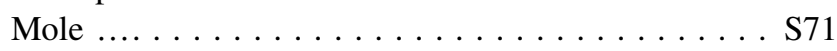

$\mathbf{N}$

Neurological disorders in pregnancy $\ldots \ldots \ldots \ldots$. . . S13

\section{O}

Osteoporosis in pregnancy .............. S8

Ovary adenocarcinoma ................ S52

Ovary benign cystic teratoma $\ldots \ldots \ldots \ldots$. . . S54, S63

Ovary sarcoma .......................... 91

$\mathbf{P}$

Pregnancy protein deficiency .............. S21

Placental abnormally ... . . . . . . . . . . . S25

Post operation complication ............. S56

$\mathbf{U}$

Uterine anomaly in pregnancy .............S31

Uterine cancer ... . . . . . . . . . . . . . . . . . . . . S68

V

Vaginal tumor................... S81

Vulva ... . . . . . . . . . . . . . . . . . . S85

Vulva-melanoma ... . . . . . . . . . . . . S87 